\title{
CUATRO VÉRTIGOS ARGUMENTALES EN LA ENSEÑANZA DE LOS DERECHOS HUMANOS. LA COMPRENSIÓN POLÍTICA Y LA ADECUADA DOCUMENTACIÓN DE LOS FENÓMENOS JURÍDICOS
}

\author{
Four argumentative vertigos in teaching human rights \\ Political understanding and right documentation of legal phenomena \\ Mario Alfredo HERNÁNDEZ SÁNCHEZ* \\ Luis González PlaCENCIA
}

\begin{abstract}
Sumario:
1. Introducción La comprensión política de los fenómenos jurídicos en la modernidad tardía 2. Primer vértigo argumental: comprender los derechos humanos implica una crítica del síndrome de Platón 3. Segundo vértigo argumental: comprender los derechos humanos implica reconocer la impronta moral de los conceptos jurídicos 4. Tercer vértigo argumental: comprender los derechos humanos implica reconocer la existencia de narrativas diversas sobre su origen 5. Cuarto vértigo argumental: comprender los derechos humanos implica posicionarse críticamente en relación con el problema de la fundamentación 6. Conclusión: la enseñanza de los derechos humanos como una tarea de comprensión
\end{abstract}

\begin{abstract}
Resumen. Este artículo define y analiza cuatro vértigos argumentales, es decir, cuatro escollos aparentemente insuperables y sobre los que existen posiciones teóricas encontradas en la argumentación en derechos humanos, mismos que dificultan los procesos de comprensión y enseñanza de los fenómenos jurídicos. Se trata del asíllamado síndrome de Platón, el fundamento moral de los conceptos jurídicos, las diversas narrativas sobre el origen del paradigma de los derechos y el problema del fundamento mismo de estos derechos. El propósito es mostrar que cualquier intento de comprender y enseñar derechos humanos tiene que hacerse cargo de estos vértigos argumentales y asumir una postura crítica.
\end{abstract}

Palabras clave: derechos humanos, comprensión, enseñanza, vértigos argumentales, espacio público, consensos sociales

\begin{abstract}
This paper defines and analyzes four argumentative vertigos, that is to say, four seemingly insurmountable obstacles on there is no theoretical consensus, and which affect argumentation in the field of human rights whilst they threaten understanding and teaching processes on the subject. These vertigos are: the so called Plato's syndrome, the moral foundation of legal concepts, divergent narratives about the origin of human rights, and the question of their foundation itself. The purpose is to show that any attempt at understanding and teaching human rights has to deal with these argumentative vertigos and adopt a critical position regarding them.
\end{abstract}

Keywords: human rights, understanding, teaching, argumentative vertigos, public space, social consensus

* Mario Alfredo Hernández Sánchez y Luis Gonzáles Placencia son profesores-investigadores de la Universidad Autónoma de Tlaxcala, respectivamente adscritos a la Facultad de Filosofía y Letras y al Centro de Investigaciones Jurídico-Políticas. Ambos son integrantes del Cuerpo Académico "Justicia internacional, contextos locales de injusticia y derechos humanos". Los autores agradecen al Programa para el Desarrollo Profesional Docente para el Tipo Superior, de la Secretaría de Educación Pública, el apoyo para el desarrollo del proyecto "Protocolo para la investigación de los fenómenos jurídicos", en cuyo contexto fue desarrollado este texto. 


\section{Introducción: la comprensión política de los fenómenos jurídicos en la modernidad tardía}

Quizá no haya otra pensadora tan interesada en el significado de la comprensión política en la modernidad tardía como la filósofa Hannah Arendt. Para ella, la tradición del pensamiento político occidental —un arco de problemas y autores que va de Platón a Karl Marx, y que tiene como rasgo común la dificultad para caracterizar positivamente a la libertad a la estabilidad ${ }^{1}$ se habría visto fracturada por el totalitarismo durante el siglo XX, en al menos dos sentidos. Primero, de manera retrospectiva, porque la teoría política, al colocar como centro de su interés a la soberanía, los arcana imperii y la ciudadanía entendida como pertenencia étnica, fue incapaz de prever que serían las propias instituciones del Estado nacional las que vulnerarían el derecho que la modernidad tardía y sus manifestaciones extremas de violencia y discriminación - como el campo de concentración o el gulag - revelaron como el fundamental, a saber, el derecho a tener derechos. Éste significaría el reconocimiento de que la persona, por el solo hecho de existir, es titular de un conjunto de protecciones jurídicas que un marco de derecho común -nacional o internacional- permitiría hacer exigibles, independientemente de restricciones ideológicas o de la razón de Estado. En este sentido, las teorías del contrato social - que constituyen el dispositivo heurístico para racionalizar la vida pública moderna - se plantearon como objetivo común justificar la obediencia ciudadana y el monopolio de la violencia legítima, caracterizando a la estabilidad del régimen de gobierno que permite la conservación de la vida y la propiedad como el valor central, en la medida que aquélla es resultado de la imposición del derecho como marco de convivencia común -incluso si esto significa la restricción de las libertades y el amurallamiento de las fronteras en torno a una identidad étnica homogénea. Con el paso del tiempo-y a partir de la Revolución Industrial y la expansión de la influencia de los países europeos, se hizo evidente que los derechos sólo tenían validez en el caso de las personas reconocidas como ciudadanas a causa de su filiación étnica y que, fuera de los Estados nacionales no parecía existir ninguna obligación de respeto hacia la integridad de quienes aparecían como extranjeros o como amenaza a la cohesión social. Así, la pérdida del derecho a tener derechos que tanto el imperialismo como el totalitarismo materializaron en la modernidad tardía no sólo consistió en la pérdida de derechos específicos, sino en la pérdida de una comunidad que quiera y pueda garantizar cualesquiera derechos ${ }^{2}$.

En segundo lugar, y de forma prospectiva, está el hecho de que la teoría política posterior al totalitarismo parecía continuar presa de las formas de razonamiento determinantes y no reflexivas - es decir, que subsumen las realidades sociales a las categorías tradicionales de comprensión política, aunque esto signifique reducir la complejidad de los hechos-, en lo que se refiere a la posibilidad de reconocer la obsolescencia de nuestros marcos normativos para lidiar con fenómenos jurídicos novedosos, como los crímenes contra la humanidad del totalitarismo. De manera particular -y después de haber asistido al juicio de Adolf Eichmann en Jerusalén, en 1961-, Arendt estaba convencida de que elucidar la responsabilidad del funcionariado nazi y de los ciudadanos europeos cómplices por omisión, a propósito del exterminio sistemático de personas judías y otros colectivos, tendría que ser la guía moral y epistemológica para generar

\footnotetext{
${ }^{1}$ De acuerdo con Arendt, en todos los grandes pensadores -incluido Platón-es llamativa la diferencia de rango entre sus filosofías políticas y el resto de sus obras. La política nunca alcanza la misma profundidad. La ausencia de profundidad de sentido no es otra cosa que la falta de sentido para la profundidad en la que la política está anclada. Esta profundidad tenía que ver, para ella, con que la acción humana que permite la ruptura con el pasado autoritario y la refundación de la autoridad en términos seculares, es impredecible a final de cuentas y no puede ser explicada por las ciencias sociales de la misma manera que las disciplinas naturales lidian con los fenómenos cíclicos. Arendt, Hannah (1997), ¿Qué es la política?, Paidós, Barcelona, 1997, p. 45.

2 Arendt, Hannah, Los orígenes del totalitarismo, Taurus, México, 2004, p. 376.

CienCIA JuRÍdicA. Departamento de Derecho. División de Derecho, Política y Gobierno, Universidad de Guanajuato - Año 6, No. 11, 2017
} 
nuevos sistemas normativos que permitieran aprehender la particularidad de los actos prohijados por un sistema político que convirtió al terror en su principio de organización y que se fijo como propósito caracterizar como superfluas las identidades de seres humanos lastrados con prejuicios y estigmas discriminatorios. Una comprensión como ésta del derecho no sólo permitiría saldar cuentas con el pasado, sino también disociar la figura de la ciudadanía de la pertenencia étnica y vincularla, más bien, con un mínimo de protecciones jurídicas inviolables -el coto vedado, según la expresión de Ernesto Garzón Valdés ${ }^{3}$ - que ninguna voluntad popular o razón de Estado podría violentar, a riesgo de cometer crímenes contra la humanidad. En el caso del nazismo, este tipo de delitos materialmente independientes de la guerra, que indicaban la existencia de una política de sistemático asesinato que continuaría en tiempos de paz [...], no estaba previsto por las normas internacionales ni tampoco por las leyes internas ${ }^{4}$. Aunque la constatación de la manera en que las personas podían ser estigmatizadas y exterminadas en ausencia de protecciones legales válidas más allá de las fronteras e instituciones de los Estados nacionales ya había producido avances en materia de derecho internacional —como la Convención para la Prevención y Sanción del Delito de Genocidio de $1948^{5}$ - lo cierto es que aún es una asignatura pendiente la comprensión acerca del papel de estos instrumentos como recursos a invocar frente a los Estados no democráticos.

Entonces, para Arendt, la pregunta es: ¿cómo comprender política y responsablemente el tiempo que nos ha tocado vivir, desde el pensamiento que sitúa a la subjetividad entre, por una parte, el peso de un pasado que parece mera acumulación de actos irracionales de violencia y, por la otra, la ansiedad frente a un futuro que amenaza con ser una reedición mas dramática de aquellos episodios de exclusión que por comodidad intelectual pensamos superados? ¿Cómo hacer frente a la perplejidad de reconocer que nuestro problema consiste en que, al parecer, no estamos ni equipados ni preparados para esta actividad de pensar, de establecernos en la brecha entre el pasado y el futuro? ¿Cómo comprender la paradójica situación del paradigma de los derechos humanos, en el que se han depositado las aspiraciones universalistas e igualitaristas del proyecto de la modernidad, pero que en el momento presente ha quedado rebasado por aquellos escenarios que evocan las patología de la modernidad y la negación sistemática de aquello que Arendt denominó el derecho a tener derechos?

El propósito de este artículo es extender el ejercicio de comprensión política para una época postotalitaria hacia el dominio de la enseñanza de los derechos humanos. Dicho ejercicio im-

3 De acuerdo con Garzón Valdés, este coto vedado incluye aquellos derechos que se traducen en bienes indispensables para la realización de los planes de vida individuales, y se constituye como el límite frente a la negociación política en democracia y al disenso ideológicamente sustentado. En este sentido, la democracia representativa se basa en la expresión de la voluntad popular pero, de manera complementaria, también en la sustracción del coto vedado de los debates y acciones legislativas. Cfr. GARzón VAldés, Ernesto (200o), "El consenso democrático: Fundamento y límites del papel de las minorías”, en: Isonomía, núm. 12, México, ITAM, pp. 7-34.

4 Arendt, Hannah, Eichmann en Jerusalén. Un estudio sobre la banalidad del mal, $3^{\circ}$ edición, Lumen, Madrid, 200o, p. 389.

5 La creación del término genocidio por Raphael Lemkin en 1946, a partir de un acto de subversión lingüística que une las raíces griega para nombra a la raza (geno) y latina para referirse al asesinato (cadere), es un ejemplo afortunado de ejercicio reflexivo de comprensión política. Hasta ese momento, para nombrar los crímenes del nazismo, se habían usado la categoría del asesinato a gran escala, lo que oscurecía tanto la motivación ideológica como el hecho de que no existía una relación directa -muchas veces, ni siquiera se conocían- entre las víctimas y los funcionarios de los regímenes autoritarios. Para una discusión sobre el origen del término genocidio y la Convención de Naciones Unidas en la materia, véase: LARA, María Pía (2009), Narrar el mal. Una teoría posmetafísica del juicio reflexionante, Gedisa, Barcelona, pp. 29-33.

6 Arendt, Hannah, Entre el pasado y el futuro. Ocho ejercicios sobre la reflexión política, Península, Barcelona, 1996, p. 28. 
plica señalar y caracterizar cuatro vértigos argumentales - el síndrome de Platón, la impronta moral de los conceptos jurídicos, la arqueología de los derechos y el fundamento mismo de éstos- para la aproximación y documentación de los fenómenos jurídicos relacionados con el paradigma garantista, frente a los cuales quienes se vinculan por los procesos de enseñanzaaprendizaje - es decir, estudiantes y profesorado - tendrían que tener una actitud de precaución y de crítica respecto de lo que han aprendido desde sus trayectorias personales y la tradición de pensamiento político. Antes de proceder con la exposición y análisis de cada uno de dichos vértigos, conviene señalar de manera breve cómo se relacionan éstos con el proceso de comprensión.

Volvamos por un momento con Arendt. Para ella, comprender es un proceso distinto de la correcta información y del conocimiento científico y, aunque nunca produce resultados inequívocos, por medio de ésta aceptamos la realidad, nos reconciliamos con ella, es decir, tratamos de sentirnos en armonía con el mundo ${ }^{7}$. Comprender es una actividad eminentemente política porque significa reconocer que la pluralidad del mundo es resultado de que éste es observado desde una diversidad de puntos de vista, y que esto influye en la conceptualización de la política en el pasado y en el presente; también significa estar dispuesto a ejercer la reflexividad para observar críticamente los propios puntos de vista e incursionar, a través de la imaginación -que para Immanuel Kant constituye una vía para la ampliación de los límites de la subjetividad y la superación del solipsismo ${ }^{8}$-, en las posiciones ajenas, para tratar de encontrar su lógica y poder situarse críticamente frente a ellas. Por eso la comprensión requiere - también y yendo más allá de la propia Arendt- el reconocimiento de que la tradición de pensamiento político ha producido lo que el filósofo mexicano Carlos Pereda ha denominado vértigos argumentales, es decir, nudos en la articulación conceptual de un tema en los que parecen converger puntos de vista encontrados que pretenden convencernos acerca de su plausibilidad para determinar el sentido futuro de la discusión. Para Pereda, se sucumbe a un vértigo argumental cuando quien argumenta constantemente prolonga, confirma o inmuniza al punto de vista ya adoptado en la discusión, sin preocuparse de las posibles opciones a ese punto de vista y hasta prohibiéndolas, y todo ello de manera, en general, no intencional ${ }^{9}$. Más aún, estos vértigos argumentales se convertirían en dispositivos conceptuales que impiden el avance de la comprensión y conducen la revisión conceptual hacia callejones sin salida, lo que significa abdicar de la posibilidad de deconstruir racionalmente una posición argumentativa y situarla en el espacio público para su crítica. En el caso del paradigma de los derechos humanos, el problema con permanecer indiferente frente a ciertos vértigos argumentales $-\mathrm{y}$ repetir acríticamente desde los procesos de enseñanza-aprendizaje que no es posible zanjar la cuestión de manera definitiva- es que no sólo se dificulta la comprensión política de nuestra relación con la tradición de pensamiento que ha conceptualizado dicho paradigma; sino que también se lastra la traducción de este esquema teórico en elementos de discusión y análisis en el espacio público que conduzcan al logro de los consensos políticos y sociales para una defensa y materialización más eficiente de los derechos humanos.

\footnotetext{
7 Arendt, Hannah, De la historia a la acción, Paidós, Barcelona, 1995, p. 29.

8 El papel de la imaginación en el proceso de comprensión es un tema de suma relevancia y complejidad. Por lo pronto, basta señalar que, para Kant, la imaginación es una herramienta creativa que establece una mediación entre el entendimiento y los sentidos con el propósito de aplicar la unidad trascendental de la conciencia al conjunto de objetos posibles de la experiencia. MAKKREEL, Rudolf A. (1990), Imagination and Interpretation in Kant: The Hermeneutical Import of The Critique of Judgment, University of Chicago Press, Chicago, p. 29 (la traducción de éste y los siguientes fragmentos de obras e inglés, es nuestra).

9 Pereda, Carlos (1994), Vértigos argumentales. Una ética de la disputa, Anthropos/ UAM-Iztapalapa, México, p. 9.
} 


\section{Primer vértigo argumental: comprender los derechos humanos implica una crítica del síndrome de Platón}

Muchas veces, la comprensión y la enseñanza de los derechos humanos se enfrenta con un escepticismo respecto de la compatibilidad del paradigma garantista con la estabilidad de las instituciones políticas. De este modo, se asume que el Estado debe conservar un cierto margen de discrecionalidad y opacidad en sus decisiones para que sus acciones sean eficientes y expeditas, como en ciertos temas de seguridad. Así, parecería que abrir al escrutinio o permitir la participación en la formación de las decisiones vinculantes - lo que significaría colocar en situación de simetría a la autoridad con la ciudadanía - sería contraproducente para la fortaleza y capacidad de respuesta de las instituciones, incluso si eso significa restringir algunas libertades particulares que deriven en el beneficio común. Esta idea tiene - de manera desafortunada - una formulación en el lugar común que frecuentemente vuelve a aparecer en los debates públicos sobre los derechos humanos y las instituciones que los tutelan acerca de que estos solo protegen a quienes han cometido un delito y, en este sentido, entorpecen la procuración de justicia. Pero, también, dicha idea se expresa en las posiciones teóricas que abogan por la validez de una razón de Estado que resulta incompatible con la intuición en el sentido de que los dere.chos humanos construyen un marco de seguridad en torno a la persona que ningún ente público o privado puede traspasar, incluso por razones instrumentales o propósitos que apunten a eficientar la acción pública. El fundamento de la versión popular y teórica de la incompatibilidad entre los derechos humanos y la estabilidad del Estado, así, tendría una doble vertiente. Una

\section{[...] consiste en la afirmación, de raíz maquiavélica, de que el poder político tiene intereses propios, distinguibles de y a veces contrarios a los de los ciudadanos; la otra [...] consiste en asociar la restricción informativa, el sofocamiento de la libertad de credo y de expresión y la prohibición del pluralismo con una salvaguarda social de la paz y el orden público ${ }^{10}$.}

Ahora bien, una crítica de esta idea desde la perspectiva de la filosofía política y el interés por mostrar la posibilidad de racionalizar la vida pública en la modernidad tardía desde un horizonte democrático están expresadas en El síndrome de Platón. En esta obra ya clásica, el filósofo político mexicano Luis Salazar plantea la existencia de una impronta del pensamiento platónico en la conceptualización posterior sobre la política, misma que se refiere a la tendencia a convertirla - y subordinarla - en un capítulo de la filosofía, en particular de la epistemología. Esto significaría que la única manera de racionalizar la vida pública sería asimilarla a un proyecto epistemológico que, primero, construyera una visión del bien que fuera absoluta e incondicionada; que se planteara después como contraintuitiva respecto de la idea popular en el sentido de que la justicia es lo que arbitrariamente los gobernantes deciden como conveniente para conservar el poder; y - finalmente- que sustrajera dicha idea del bien de la negociación desde los intereses y visiones morales particulares. Así, el desorden, la maldad, los conflictos y las violencias del mundo político se derivarían [...] de la ignorancia y de las opiniones falsas e infundadas [...] en relación a lo que es verdaderamente bueno [...], tanto individual como colectivamente $^{11}$. Para Platón el caos que parece dominar a la política, y la causa que de muchos hombres sabios hayan declarado su intención de alejarse del dominio de lo público, no se puede conjurar creando leyes que mejor reflejen los interés del pueblo o ampliando la participación política y, en consecuencia, permitiendo que también los extranjeros, los esclavos o las mujeres

\footnotetext{
${ }^{10}$ Rodríguez ZePeda, Jesús (2004), Estado y transparencia. Un paseo por la filosofía política, IFAI, México, p. 23.

${ }^{11}$ Salazar, Luis (1997), El síndrome de Platón. ¿Hobbes o Spinoza?, UAM-Azcapotzalco, México, p. 47.
} 
ejerzan la ciudadanía; sino, más bien, encontrando los criterios de racionalidad externos a la propia práctica política, que permitan establecer los parámetros de verdad y moralidad que habrán de guiar la organización del Estado.

Salazar sitúa al resentimiento como el motivo profundo del síndrome de Platón. Acaso el más dramático de los diálogos platónicos, la Apología de Sócrates, da cuenta del crimen que la democracia ateniense habría cometido contra el hombre más justo y sabio de la ciudad, a causa de acusaciones infundadas acerca de impiedad y corrupción de la juventud. En realidad - parece querer decirnos Platón-Sócrates, quien lo único que hacía era motivar a los ciudadanos a examinar públicamente sus creencias más arraigadas e irreflexivas sobre la política, se convirtió en un criminal sólo porque la democracia había invertido los valores y permitido la primacía de la política sobre la filosofía; es decir, dejando que la mayoría que se guía por las pasiones y las apariencias decidiera los estándares legales con que se juzgan las acciones que ocurren en el espacio público. Porque lo condenable no fue sólo que Sócrates destruyera las certezas de los más jóvenes, sino que mostrara que los políticos defienden posiciones que no se sostienen lógicamente y que el pueblo los aclama sólo porque teme las consecuencias de la desobediencia. De manera irónica Sócrates, casi al inicio de la Apología, afirma de un político del que no recuerda su nombre, pero que podría ser cualquiera, lo siguiente: me pareció que otras muchas personas creían que ese hombre era sabio y, especialmente, lo creía él mismo, pero que no lo era [...] Parece, pues, que al menos soy más sabio que él en esta misma pequeñez, en que lo que no sé tampoco creo saberlo ${ }^{12}$.

¿Cuál es la consecuencia de esta inversión de valores para la razón práctica? En opinión de Salazar, el síndrome de Platón tiene como consecuencia que la justicia por estos crímenes nefandos cometidos en nombre de la democracia la articula la filosofía a partir de revelar la vacuidad y falsedad de la vida pública así concebida. La gran revancha del filósofo, modelo de vida justa, contra sus acusadores injustos pero poderosos, será mostrarles a estos [y] al mundo, la intrascendencia de sus ambiciones, de sus luchas y de sus aparentes victorias en la plaza pública ${ }^{13}$. Así, a partir de esta marca sobre el pensamiento de la política es que los proyectos de racionalización de la vida pública en la modernidad - por supuesto, un horizonte más complejo que la Antigüedad clásica-continuarían presos de las metáforas organicistas para explicar el orden social y, entonces, observarían a la pluralidad y a las libertades individuales que son consecuencia del ejercicio de los derechos en los sistemas democráticos, como una amenaza para la estabilidad y preservación del cuerpo político en su conjunto. En efecto, si el régimen de gobierno ideal para Platón es una sofocracia, es decir, con el rey filósofo a la cabeza, la obediencia a sus mandatos y la disposición del resto de la población a ocupar las posiciones sociales relacionadas con la milicia, la administración económica y la producción de bienes de consumo, se fundamenta en la concepción del cuerpo político como un organismo vivo, cuya salud es producto de la especialización y coordinación de los órganos que lo integran. Para Platón, de la misma manera que es irracional que el sistema digestivo que provee los nutrientes al cuerpo subordine al alma porque los fines de ésta son superiores a los de aquél, sería insensato encomendar el gobierno a quién sólo sabe hacer la guerra o arar la tierra, puesto que aunque estas personas saben hacer un trabajo que es rutinario, ellas no conocen el bien absoluto hacia el que el Estado debe orientarse.

Debe recordarse que la filosofía política platónica está dominada por las metáforas médicas, lo que apunta a distinguir una visión sobre la política fundada en la opinión de un punto de vista filosófico que estaría basado en el conocimiento auténtico; es decir que, aunque muchas

\footnotetext{
${ }^{12}$ Platón (2014), Apología, Gredos, Madrid, 21d-c.

${ }^{13}$ SAlazAR, Luis, op. cit. nota 11, p. 14.

CIENCIA JuRíDICA. Departamento de Derecho. División de Derecho, Política y Gobierno, Universidad de Guanajuato - Año 6, No. 11, 2017
} 
personas, dada su experiencia en materia de herbolaria podrían aconsejar sobre lo que conviene en caso de una enfermedad, solo los médicos conocen en realidad el efecto de las medicinas sobre el cuerpo y pueden actuar en base a explicaciones generalizables e independientes de la relación con la persona enferma ${ }^{14}$. Por analogía puede afirmarse que, aunque muchas personas pueden concebir opiniones acerca de lo que debería ser el propósito de la política a partir de su posición en la escala social -acabar con la pobreza, combatir la injusticia, promover la igualdad entre hombres y mujeres-, sólo unos pocos conocerían el auténtico fin de la política, que es universal e imperecedero - promover el supremo bien a través de las instituciones del Estado. Así, en la argumentación de la República sobre el régimen de gobierno ideal, y a propósito del lugar del filósofo en éste, Sócrates afirma que

[...] gracias al grupo humano más pequeño, que es la parte de él mismo que está al frente y gobierna, un Estado conforme a la naturaleza ha de ser sabio en su totalidad. Y de este modo, según parece, al sector más pequeño por naturaleza le corresponde el único de estos tipos de conocimiento que merece ser denominado "sabiduría"15.

Para Luis Salazar, el síndrome de Platón vigente aún en las explicaciones modernas sobre la política hace que se tenga una actitud de desprecio o escepticismo respecto de la democracia y su defensa de la pluralidad y las libertades individuales, o bien que se asuma que el gobierno debe reducirse a un catálogo de medidas de reingeniería social que permitan que cada ciudadano tome su lugar en la cadena de actos burocráticos que derivan en la estabilidad del régimen de gobierno. Entonces, ¿por qué la enseñanza de los derechos humanos implica una toma de posición crítica respecto del síndrome de Platón? Porque comprender la importancia del paradigma garantista en la modernidad tardía supone una valoración positiva de la pluralidad social, del disenso y de las objeciones de conciencia frente a los determinismos de clase o historicistas. Todos estos son elementos contrarios a la fundamentación filosófica del Estado que hizo Platón en la República y que Karl Popper — de manera no exenta de inconsistencias argumentativascalificó como el modelo de una sociedad cerrada ${ }^{16}$. La necesidad de introducir criterios externos a la práctica política y que se asocian a una visión de la filosofía como empresa epistemológica contraintuitiva que busca la verdad eterna e inmutable de la cual el mundo común sería sólo un pálido reflejo, impide valorar positivamente al espacio público como el ámbito de encuentro entre quienes son diversos, pero que aún así pueden generar formas de solidaridad y cooperación que se fundamentan en el reconocimiento mutuo de su igualdad. Así, la persistencia de la tradición instaurada por Platón habría impedido — entre otras cosas — la inclusión del paradigma de los derechos humanos, su fundamentación, coherencia y alcances como problemas legítimos del dominio de la teoría política, incluso en la modernidad tardía: precisamente, cuando nos percatamos de que el mal radical - a diferencia de lo que afirma Platón en la Apología - no se hace sólo por ignorancia y que puede ser producto de la negación sistemática y dirigida desde las instituciones del Estado nacional del derecho a tener derechos. Para Luis Salazar, tomar distancia crítica respecto del síndrome de Platón —entender que éste puede convertirse en un

\footnotetext{
${ }^{14}$ Martha Nussbaum ha señalado que éste es un rasgo común a la filosofía práctica antigua: plantear una asimetría entre quien conoce - como el médico-y quien no conoce - el paciente. Incluso un pensador como Aristóteles, tan favorable a sistematizar y racionalizar las experiencias particulares de las personas, concede implícitamente que la medicina posee una asimetría intelectual en este punto. Sus beneficios prácticos requieren que el doctor conozca, pero no que el paciente conozca; los logoi de la medicina son autoritarios y unilaterales. NussBAUM, Martha C. (2003), La terapia del deseo. Teoría y práctica en la ética helenística, Paidós, Barcelona, p. 100.

15 Platón (2014), República, Gredos, Madrid, 2014, 429a.

${ }^{16}$ Cfr. Popper, Karl (1957), La sociedad abierta y sus enemigos, Paidós, Buenos Aires.
} 
vértigo argumental que impide la valoración positiva de la pluralidad social- significa asumir que las instituciones democráticas que fundamentan su legitimidad en el respeto irrestricto a los derechos tienen que priorizar los criterios de la política sobre los de la filosofía, con el propósito de lograr acuerdos incluyentes y que permitan una eficiente protección de la dignidad en escenarios tan injustos y violentos como los nuestros:

Más bien, reconociendo el papel que los elementos cognitivos juegan en la configuración efectiva de los deseos y las pasiones, habría que apelar a la formación de contextos de exigencia razonables, a combinaciones de racionalidad pragmáticas y éticas plurales con marcos institucionales reguladores y sancionadores de las conductas sociales ${ }^{17}$.

\section{Segundo vértigo argumental: comprender los derechos humanos implica reconocer la impronta moral de los conceptos jurídicos}

Otro de los obstáculos para la comprensión y enseñanza de los derechos humanos —afianzado desde posiciones que reducen la racionalidad occidental a un modo de dominación que produce sociedades colonizadoras y periféricas - radica en que se les caracteriza, en el mejor de los casos, como un catálogo de buenas intenciones que resultan secundarias frente a los imperativos descarnados de la política; o, en el peor, como una justificación para la imposición de modos de vida y creencias que de hecho constituyen una violencia contra los usos y costumbres de las comunidades tradicionales. Desde este punto de vista, la pretendida globalización de un proyecto de liberación asociado a los derechos humanos se descubre [...] en contradicción consigo mismo, ya que la mayoría de sus posibles participantes afectados se encuentran privados de cumplir con las necesidades que el mismo sistema ha proclamado como derechos ${ }^{18}$.

Si bien es cierto que el paradigma de los derechos humanos en el momento presente enfrenta una crisis respecto de su traducción en consensos ciudadanos en sociedades con profundos déficits democráticos, también es verdad que se trata de un movimiento fundamentado en la universalidad de ciertos valores asociados a la dignidad humana y que busca maneras creativas de darles realidad y hacerlos compatibles con las distintas tradiciones políticas. Esto implica asumir que ninguna conquista normativa orientada a un tratamiento igualitario de las personas, o ninguna protección legal destinada a frenar los poderes fácticos, puede pasar por alto el contexto local desde el que se interpreta el paradigma de los derechos humanos y que, al contrario, éstos tienen que poder reconstruirse desde las experiencias particulares de exclusión y violencia. En este sentido, Seyla Benhabib ha acuñado el concepto de iteración democrática para describir la manera en que la unidad y diversidad de los derechos humanos es configurada y reconfigurada en esferas públicas fuertes y débiles, no sólo en legislaturas y cortes, sino de manera más efectiva desde los movimientos sociales, los actores de la sociedad civil y las organizaciones transnacionales ${ }^{19}$.

Esta forma de situar al paradigma de los derechos en los espacios públicos para su revisión desde la razón práctica, pero también desde las expectativas ciudadanas, implica evidenciar que los elementos conceptuales que lo articulan — principalmente, las ideas de autonomía, igualdad, libertad y dignidad-, aunque tienen un origen moral asociado a tradiciones éticas occidentales, pueden ser traducidos política y jurídicamente para fundamentar luchas por la inclusión y el reconocimiento en contextos discursivos y culturales alternativos. No es casual -afirma Nor-

\footnotetext{
17 SAlazAR, Luis, op. cit. nota 11, p. 400.

${ }^{18}$ Dussel, Enrique (1998), Ética de la liberación en la edad de la globalización y la exclusión, Trotta, Madrid, p. 310-311.

19 Benhabib, Seyla (2011), Dignity in Adversity. Human Rights in Turbulent Times, Polity, Londres, p. 15. 
berto Bobbio- que estos conceptos hayan encontrado su expresión racional y racionalizada en la doctrina iusnaturalista, cuyas reflexiones se iniciaron considerando al individuo como una persona moral, dotada de derechos que le pertenecen por naturaleza y como tales son inalienables e inviolables ${ }^{20}$. De este modo, los tratados y convenciones del derecho internacional público - en donde localizamos nuestros referentes contemporáneos de autonomía, igualdad, libertad y dignidad - deberían dejar de ser observados como conquistas consumadas y, más bien, ser entendidos como puntos de partida para el surgimiento de movimientos transnacionales que se enfrenten a los poderes fácticos también transnacionales, reclamando los derechos más allá de las fronteras, a través de modalidades de iteración democrática interdependientes y, también, de reinvenciones y nueva apropiaciones de normas valiosas que frecuentemente han sido malentendidas y objeto de abuso al momento de su aplicación ${ }^{21}$.

Es el filósofo alemán Jürgen Habermas quien se ha esforzado, en su obra reciente, por mostrar que el paradigma de los derechos humanos puede reconstruirse en el contexto de una racionalidad deliberativa que - a diferencia del síndrome de Platón - busca articular los criterios de validez de las normas del derecho en el espacio público, de cara no sólo a las distintas posiciones sociales y sus tradiciones morales, sino también atendiendo a los reclamos de inclusión y reconocimiento que han formulado los movimientos sociales a partir de la segunda mitad del siglo XX. La intuición fundamental de Habermas es que que dichos movimientos sociales - surgidos desde luchas tan disímbolas como las que se han generado en contra del racismo, la misoginia, la pobreza o la contaminación - han podido converger en el paradigma de los derechos humanos porque el contenido moral de las ideas de autonomía, igualdad, libertad y dignidad que lo han configurado en la modernidad, se ha incorporado en los distintos instrumentos de derecho doméstico e internacional después de ser traducido primero política y después jurídicamente. Así, la justicia, para Habermas, se amplía en la arena de las luchas sociales:

Los sistemas han de seguir ejecutando sus propias melodías, pero con un ritmo distinto, establecido por un cambio de acentos. Con este fin, el derecho civil concebido hasta ahora en términos individuales, ha de transferirse a actores colectivos y cambiar en su enfoque de relaciones entre personas a relaciones sistémicas [...] El derecho no puede ni debe implementarse sentando de forma autoritaria objetivos de control y regulación, antes en forma de "programas relacionales" que motiven al sistema generador de peligros a cambiar de rumbo y lo pongan también en situación de hacerlo. De este modo, el derecho funciona como catalizador de cambios que el propio subsistema de que se trate efectúa sobre si mismo ${ }^{22}$.

En este sentido, los derechos humanos constituyen un paradigma que nos permite construir canales de comunicación entre, por una parte, quienes han experimentado la opresión y la exclusión y, por la otra, quienes toman las decisiones vinculantes en las arenas legislativa y ejecutiva, porque sus conceptos morales fundantes han experimentado un proceso de traducción política y jurídica que les permite presentarse como parte de una idea de razón pública liberada de pretensiones colonizadoras. Las tradiciones filosóficas modernas - de manera particular el kantismo- constituyen un marco normativo para pensar la manera de dar realidad a la autonomía en su dimensión personal y colectiva. No obstante, son las luchas concretas por la inclusión y el reconocimiento durante el siglo XX las que se han apropiado de estos conceptos morales y los han traducido en un vocabulario político y no metafísico donde la pluralidad de actores

\footnotetext{
${ }^{20}$ Bobbio, Norberto (2003), Teoría general de la política, Trotta, Madrid, p. 409.

${ }^{21}$ Benhabib, Seyla, op. cit. nota 19, p. 15.

${ }^{22}$ Habermas, Jünger (200o), Facticidad y validez. Sobre el derecho y el Estado democrático de derecho en términos de teoría del discurso, 2da. ed. Trotta, Madrid, pp. 424-425.
} 
sociales puede reconocerse; también, son los movimientos sociales los que han visibilizado en el espacio público las consecuencias de los poderes fácticos que amenazan con despojar a las personas de su autonomía y libertad, al tiempo que devalúan el sentido compartido de la igualdad y la dignidad. Como ejemplo, Habermas refiere el caso de la lucha por el reconocimiento y garantía de los derechos de las mujeres, que une a los diversos feminismos en la crítica de la incapacidad del Estado para trascender la igualdad formal y se posiciona contra el supuesto de que la igualdad de derecho de los géneros puede conseguirse dentro del marco institucional existente y dentro de una cultura definida y dominada por los hombres ${ }^{23}$. Solo después de que los conceptos morales asociados al paradigma de los derechos humanos son enarbolados como banderas por aquellas luchas políticas que disputan en el espacio público la comprensión tradicional del papel de las instituciones democráticas, es que la idea de justicia puede ampliarse y producir sistemas de derecho que incorporen al paradigma garantista. Por supuesto, no se trata de un proceso terso o solamente progresivo. En la historia reciente hemos constatado, por ejemplo, cómo las conquistas del pasado en el sentido de ampliar e institucionalizar el alcance de los derechos humanos son sometidas a nuevas disputas o revisiones en el espacio público. De nuevo, por ejemplo, estamos discutiendo la amplitud de las acciones afirmativas que benefician a las mujeres, sobre los deberes de las generaciones presentes hacia las futuras en materia de protecciones ambientales, o acerca de si el discurso de odio puede estar o no amparado por la libertad de expresión. Por eso mismo, la comprensión y enseñanza de los derechos humanos no puede desconocer esta historia de desplazamientos semánticos — desde la ética y la política hacia el derecho- que han permitido volverlos vinculantes y exigibles.

¿Qué significa que el derecho dejé de ser observado como un conjunto de normas positivizadas cuya vigencia configura el Estado de derecho y, en su lugar, sea concebido como una instancia de mediación permanente entre la universalidad de la dignidad a que apuntan dichas normas y las maneras en que los distintos movimientos sociales han hecho sus aportaciones semánticas para ampliar y profundizar la idea de justicia? Habermas considera que el paradigma contemporáneo de los derechos puede entenderse como un capítulo que la modernidad tardía habría añadido a la razón práctica en sentido kantiano. Ésta, entendida como un dominio que surge a partir de la capacidad de los seres humanos para ejercer su libertad a través del paradójico acto de limitar sus acciones de acuerdo con reglas de conducta que concebimos como universalizables y que, adicionalmente, nos permiten reconocer nuestra dignidad inalienable, al tiempo que proyectamos estas aspiraciones civilizatorias, tanto en nuestros semejantes como en las instituciones que creamos y obedecemos. Hoy, tenemos que comprender al paradigma garantista como el ámbito teórico y práctico que permite a las personas observarse reflexivamente como capaces de determinar de manera autónoma los parámetros de comportamiento ético que sean universalizables; $y$, de manera complementaria, como posibilitadas de definir los estándares de justicia que permitan reconocer a la obediencia y la conformidad de la voluntad con las instituciones del Estado, como actos que emergen de la propia personalidad moral. Lo anterior, con la conciencia de que la modernidad tardía ha generado modalidades de vulneración de dicha personalidad que no sólo se relacionan con la heteronomía o la mala fe, sino con formas extremas de erradicación de la dignidad —el genocidio, la migración forzada, la pobreza o la impunidad-que contradicen la imagen de progreso moral que a Kant le resultaba necesaria de inferir del relato histórico. En consonancia con Habermas, podemos señalar que la comprensión y enseñanza de los derechos humanos tendrían que permitirnos, más bien, actualizar la intuición kantiana en el sentido de que la vinculación intrínseca.

${ }^{23}$ Ibid. p. 507.

CIENCIA JuRíDICA. Departamento de Derecho. División de Derecho, Política y Gobierno, Universidad de Guanajuato - Año 6, No. 11, 2017 
[...] entre soberanía popular y derechos del hombre ha de radicar, pues, en el contenido normativo de un modo de ejercicio de la autonomía política, que no viene asegurado por la forma de leyes generales sino solo por la forma de comunicación que representa la formación discursiva de la opinión y la voluntad comunes ${ }^{24}$.

\section{Tercer vértigo argumental: comprender los derechos humanos implica reconocer la existencia de narrativas diversas sobre su origen}

La omnipresencia del lenguaje de los derechos humanos en los medios de comunicación, los debates en la esfera pública, los discursos políticos y en la diversidad de reclamos de inclusión y reconocimiento formulados desde distintas posiciones sociales, hace parecer que este paradigma siempre ha estado presente. Incluso, el desencanto a propósito de las posibilidades reales de su plasmación, que convierte a las tareas de comprensión y enseñanza de esta materia en esfuerzos a contracorriente de la opinión mayoritaria, se traduce en una confusión sobre la conveniencia de frasear o no en el vocabulario de los derechos las demandas que formulan los actores sociales peroféricos. Así, hoy existen reclamos -que se pretenden filtrados por el paradigma garantista- para que los marcos normativos y las instituciones democráticas reconozcan y destinen recursos a garantizar, por ejemplo, los derechos de los animales, el derecho al orgasmo, a proferir discursos de odio, a atrincherar las fronteras frente a los migrantes o a portar armas de fuego. Entonces, el énfasis en los derechos ha producido un descuido en torno a la construcción de instituciones y mecanismos para garantizarlos efectivamente, para lo cual el lenguaje de los deberes $y$ las responsabilidades es fundamental ${ }^{25}$. ¿Cómo hacemos, entonces, para separar un auténtico derecho que merece rango constitucional o que aspire a lograr el consenso internacional, de una pretensión de reconocimiento que no conviene universalizar dado su carácter idiosincrático?

Una forma de ponderar la idoneidad de una pretensión de inclusión o reconocimiento para ser reconocida como derecho es revisar su compatibilidad con las protecciones que, a lo largo de la historia del paradigma garantista, se han mantenido en su núcleo o se le han ido incorporando a causa de su respaldo ciudadano o la evidencia de las condiciones sociales que amenazan con vulnerar la dignidad. Mejor aún, la comprensión y enseñanza de los derechos humanos tendría que enriquecerse con las herramientas de la arqueología del saber en el sentido que Michel Foucault la enunció para, partiendo del protagonismo actual del lenguaje de los derechos, rastrear el momento en que éstos se convirtieron - parafraseando a Samuel Moyn - en la última utopía. Glosando el método foucaultiano, Sergio Pérez ha señalado que la arqueología niega a los objetos de las ciencias humanas cualquier origen empírico y todo asomo de evidencia. Ella los convierte en entidades discursivas y, tratándolos como acontecimientos, afirma que están firmemente anclados a sus condiciones de enunciabilidad ${ }^{26}$. Para el caso de los derechos humanos - y desde la conciencia de la omnipresencia de su lenguaje y la diversidad de reclamos morales que aspiran al reconocimiento- lo relevante sería rastrear el momento en que estos se convirtieron en una lingua franca para frasear, por una parte, la pretensión normativa de colocar en situación de simetría a quienes gobiernan y quienes son gobernados, en lo que se refiere a la existencia de un ámbito de la personalidad jurídica — precisamente tejido por el alcance y extensión de los derechos- que no puede ser traspasado por ningún poder público o privado; $y$, por la otra, para enunciar los bienes y libertades asociados a una vida de calidad, distinta de la

\footnotetext{
${ }^{24}$ Ibid. p. 168.

${ }^{25}$ Cruz Parcero, Juan Antonio (2012), El lenguaje de los derechos. Ensayos para una teoría estructural de los derechos, Trotta, Madrid, 2012, p. 172.

${ }^{26}$ Pérez, Sergio (2001), "La arqueología y la genealogía tal como yo las entiendo”, en: Estudios Políticos, núm. 18, Medellín, Universidad de Antioquia, p. 156.
} 
mera sobrevivencia o la existencia con temor a experimentar sin protección alguna los efectos de la violencia o la discriminación.

Para esquematizar los vértigos argumentales a que puede conducir obviar la existencia de arqueologías divergentes respecto del paradigma de los derechos humanos como un saber que vuelve relevantes pretensiones normativas y expectativas ciudadanas, pero que también ha obligado a una reconfiguración de los principales conceptos de la teoría política y jurídica, podemos tomar como tipos ideales tres narrativas que difieren en la temporalidad y alcances.

En primer lugar, está lo que podemos llamar la narrativa ilustrada, sostenida por Lynn Hunt en su libro La invención de los derechos humanos (2007), que localiza en las Revoluciones de Independencia de Estados Unidos y la Francesa del siglo XVIII el surgimiento una conciencia y tematización ilustrada de la subjetividad que la vuelve portadora de derechos inalienables y que motiva a los ciudadanos, organizados frente al poder despótico, a exigirlos públicamente y plasmarlos en cartas de derechos. Para Hunt, los derechos humanos -incluso si como ha denunciado el feminismo nacieron indisolublemente ligados a una visión androcéntrica y patriarcal de la ciudadanía ${ }^{27}$ - se convirtieron en verdades evidentes - como puede leerse al inicio de la Declaración de Independencia de Estados Unidos de 1776- con la suficiente fuerza moral como para iniciar una reacción en cadena para ser reconocidos en los distintos ordenamientos constitucionales posteriores. De acuerdo con Hunt, la razón de esta escalada progresista es la transformación radical de la manera en que las personas se observaron a sí mismas a partir de la modernidad ilustrada. En este sentido, la "empatía imaginada" sirve de fundamento de los derechos humanos más que del nacionalismo. Es imaginada, pero no en el sentido de inventada, sino en el de que [...] requiere un acto de fe, de imaginación, para asumir que otra persona es igual que tú ${ }^{28}$. Como señaló Arendt inspirada en Kant, la Ilustración significó que el ser humano - por fin- aprendió a pensar su autonomía en un sentido político, es decir, siguiendo las máximas de un sensus communis: pensar por uno mismo (la máxima de la Ilustración); situarse con el pensamiento en el lugar del otro (la máxima de la mentalidad 'amplia'); y la máxima del pensamiento consecuente: estar de acuerdo con uno mismo ${ }^{29}$. Hunt afirma que la revolución de la subjetividad moderna que alumbró la evidencia de los derechos humanos tiene un correlato literario en el surgimiento de la esfera pública como un ámbito para la discusión de las cartas y novelas que ahora exhibían sin pudores las cavilaciones de la individualidad dividida entre las demandas de la ética y la política; uno sociológico, manifiesto en la proliferación de espacios de asociación — sindicatos, grupos estudiantiles, partidos políticos- que surgen como espacios para la acción concertada entre quienes se consideran mutuamente libres e iguales; y, por supuesto, uno económico relacionado con la consideración del mercado como fuente de igualación en vista de la libre competencia entre quienes poseen diversos talentos y capacidades para generar riqueza. Para Hunt, aunque esta historia aún no ha conocido un final feliz, lo importante es la centralidad de la subjetividad y los sentimientos morales que implican un reconocimiento del carácter fundador de los derechos para la modernidad ilustrada. Por tanto, una narrativa como ésta demuestra que al final la mejor defensa de los derechos son los sentimientos,

\footnotetext{
${ }^{27}$ En este sentido, las mujeres habrían sido excluidas del proyecto emancipatorio de la modernidad porque la multitud de pensadores ilustrados parecen coincidir en lo siguiente: las mujeres no son individuos porque, por principio, son consideradas como género, como un colectivo que contrasta, en una oposición de cosas de distinta especie, con los hombres, no considerados como otro conglomerado con diferente sexo, sino como un conjunto de individuos, de sujetos autónomos. SERret, Estela (2002), Identidad femenina y proyecto ético, PUEG/ UAMAzcaptzalco, México, p. 50.

${ }^{28}$ Hunt, Lynn, La invención de los derechos humanos, Tusquets, Barcelona, 2009, p. 31.

29 Arendt, Hannah (2003), Conferencias sobre la filosofía política de Kant, Paidós, Barcelona, p. 131. 
las convicciones y las acciones de multitudes de individuos que exigen respuestas acordes con su sentido interno para la indignación ${ }^{30}$.

Por su parte, Norberto Bobbio, en su libro El tiempo de los derechos (1990), es partidario de una narrativa internacionalista de los derechos humanos, denominada así a causa de su énfasis en los instrumentos de derecho internacional - fundamentalmente asociados al surgimiento del Sistema de Naciones Unidas-, que serían observados como la traducción legal de un consenso transnacional sobre la deseabilidad de un marco de protecciones válido más allá de los Estados nacionales, sobre todo en vista del despojamiento de la ciudadanía que ocurrió durante el nazismo y otros movimientos autoritarios del siglo XX. En efecto, para Bobbio, durante la época de la Guerra Fría, la atención hacia la amenaza para la humanidad que representaba una potencial confrontaciones entre las dos grandes potencias mundiales - Estados Unidos y la Unión Soviética-, motivó a los países a generar convenciones centradas en los derechos humanos para sustituir a los tratados que surgieron paralelamente a la consolidación de los Estados nacionales para regular los posibles conflictos bélicos entre éstos. Las acciones transnacionales a favor de la paz gradualmente habrían definido los temas que, de forma complementaría, los Estados tendrían que resolver en el ámbito doméstico y en coordinación con otros países para asegurar la estabilidad y la justicia social. Así, la adopción por parte de los países que conforman el Sistema de Naciones Unidas del Pacto Internacional de Derechos Civiles y Políticos, el Pacto Internacional de Derechos Económicos, Sociales y Culturales (ambos de 1966), la Convención Internacional sobre Toda Forma de Discriminación Racial (1965), la Convención sobre la Eliminación de Todas las Formas de Discriminación contra la Mujer (1979), la Convención contra la Tortura y otros Tratos o Penas Crueles, Inhumanos o Degradantes (1984), la Convención sobre los Derechos de la Niñez (1989), la Convención Internacional sobre la Protección de los Derechos de Todos los Trabajadores Migrantes y sus Familiares (1990), la Convención sobre los Derechos de las Personas con Discapacidad y la Convención Internacional para la Protección de Todas las Personas contra las Desapariciones Forzadas (ambas de 2006), constituye un catálogo de prioridades en la agenda de los derechos humanos. Ahora bien, la proliferación de estos instrumentos internacionales, de acuerdo con Bobbio, habría producido la paradójica situación del tiempo de los derechos: por una parte, contamos con este arsenal normativo y comités de seguimiento y evaluación sobre la manera en que los países dan cumplimiento a dichos compromisos internacionales; pero, por la otra, nunca antes en la historia de la humanidad se han producido y documentado tal cantidad y crueldad de violaciones a derechos humanos que no han podido ser frenadas desde el Sistema de Naciones Unidas. Entonces, para Bobbio, la lección del tiempo de los derechos consiste no en añorar una época donde la soberanía de los Estados era la condición para la protección de la vida y la integridad de las personas; sino, más bien, continuar profundizando la marcha del paradigma de los derechos en un sentido universalista y transnacional, considerando que todavía la Declaración Universal de los Derechos Humanos, de 1948, tiene un potencial crítico para regular relaciones entre particulares, entre ciudadanos y gobiernos y entre países que, en ausencia de este fundamento civilizatorio, reproducirían el estado de naturaleza hobbesiano:

Como las declaraciones nacionales fueron el presupuesto necesario para el nacimiento de las democracias modernas, la Declaración Universal de los Derechos Humanos, ¿no es por fuerza el presupuesto de la democratización del sistema internacional, del cual dependen el final del

$\overline{30}$ Hunt, Lynn, op. cit. nota 28, pp. 219-220. 
sistema tradicional del equilibrio, en el que la paz es siempre una tregua entre dos guerras, y el inicio de una era de paz estable que no tenga nunca más a la guerra como alternativa? ${ }^{31}$

Finalmente, ha sido Samuel Moyn, en su libro The Last Utopia (2010), quien se ha mostrado crítico de ambas narrativas de los derechos humanos al plantear, a través de lo que podemos denominar la narrativa estratégica, cómo estos se convirtieron - en un momento tan reciente como la década de 1970 - en bandera de lucha para los movimientos sociales a causa del agotamientos de las utopías ilustradas y revolucionarias, tanto centradas en las instituciones estatales como en los acuerdos internacionales.

Aunque nacieron como una alternativa a los propósitos políticos grandilocuentes -o incluso como una crítica moral hacia la política- los derechos humanos fueron forzados a apropiarse de la descomunal misión política de suministrar un marco global para la protección de la libertad, la identidad y la prosperidad. Este paradigma fue obligado, gradual pero insistentemente, a asumir el mismo maximalismo que había logrado evitar ${ }^{32}$.

La intención de Moyn es mostrar que el contemporáneo paradigma de los derechos humanos, centrado en los acuerdos internacionales y el combate coordinado transnacionalmente de los grandes problemas que aquejan a la humanidad como la pobreza, la contaminación o las migraciones, no es consecuencia - como afirma Lynn Hunt - de los movimientos ilustrados contrarios a los regímenes autoritarios del siglo XVIII, ya que los revolucionarios modernos aspiraban de manera prioritaria a tomar control de las instituciones políticas tradicionales $y$ universalizar el voto; pero tampoco podría remontarse - como supone Bobbio- a los acuerdos internacionales derivados de la Segunda Guerra Mundial y la intención de llevar ante tribunales internacionales a los perpetradores de los crímenes totalitarios, dado que la coordinación internacional se habría reducido al acompañamiento de los procesos locales de justicia transicional. Para Moyn, tanto la narrativa ilustrada como la internacionalista pierden de vista el carácter estratégico que los ha convertido en bandera de lucha para los movimientos sociales a partir de la década de 1970. En efecto, las mujeres, los grupos raciales, el colectivo LGBTI o las asociaciones para la defensa de las personas migrantes - por citar solo algunas de las causas recientes políticamente mas creativas y exitosas - han encontrado en el paradigma garantista una bandera de lucha que evoca en la opinión pública el potencial libertario que las utopías revolucionarias no pudieron concretar; y, también, la posibilidad de construir vínculos solidarios y productivos entre todas las personas que han sido afectadas por las decisiones autoritarias o las zonas de opacidad y discrecionalidad en los sistemas democráticas. Esta historia reciente de lucha contra el poder desde quienes carecen de poder, y de crítica hacia los poderes fácticos y los gobiernos cómplices que empobrecen, contaminan y polarizan socialmente los espacios locales, es demasiado importante para ser desestimada o reducida a un capítulo de la modernidad ilustrada. A fin de cuentas, el reclamo de Moyn a quienes el día de hoy se proponen comprender y enseñar los derechos humanos es la tendencia a romantizar la historia que ha dado origen a este paradigma, y hacer parecer como lineal y tersa una visión del progreso que parecería una promesa igual de utópica que la que realizaron los movimientos de inspiración marxista:

En vez de volver a la historia para hacer un monumento a los derechos humanos enraizándolos tan profundo en el pasado, es mejor reconocer lo reciente y contingentes que en realidad son. Sobre todo, es vital vincular el surgimiento de los derechos humanos con la historia de los

\footnotetext{
${ }^{31}$ Boвbio, Norberto (1990), El tiempo de los derechos, Sistema, Madrid, p. 149.

32 Moyn Samuel (2010), The Last Utopia, The Belknap Press of Harvard University Press, Cambridge, p. 9. 
movimientos utópicos - con el sincero deseo de hacer del mundo un mejor lugar. Que se trata sólo de una forma de utopía entre muchas-de hecho una que permanece el día de hoy porque ha sorteado las tormentas que han hundido a otras- es algo que debe quedarnos claro ${ }^{33}$.

\section{Cuarto vértigo argumental: comprender los derechos humanos implica posicionarse críticamente en relación con el problema de la fundamentación}

De manera frecuente, la comprensión y enseñanza de los derechos da por sentado que la fundamentación de estos se resuelve refiriéndolos al derecho positivo, es decir, al texto constitucional y las legislaciones secundarias que los incluyen. No obstante, esta visión convierte al problema del fundamento de los derechos en un asunto de ingeniería institucional y de reconstrucción genética del poder político, más no sobre la racionalidad de las normas y la visión de la vida pública que sustentan. Por esta razón, conviene observar el problema del fundamento desde las herramientas de la filosofía del derecho, tal y como ha hecho Luigi Ferrajoli.

El problema del fundamento de los derechos, para Ferrajoli, se ha entendido en al menos cuatro sentidos distintos: primero, como razón teórica; segundo, como fuente jurídica; tercero, como justificación axiológica; y cuarto, como origen histórico o sociológico. De entre estas posibles soluciones, la que interesa por su carácter filosófico-político a Ferrajoli es la que alude al fundamento axiológico y que es respuesta normativa a la pregunta acerca de cuáles son los derechos que deberían ser tutelados como fundamentales. Para Ferrajoli, esta respuesta exige la formulación de cuatro criterios morales - de inspiración kantiana- que permiten configurar el valor de la persona considerada como fin y nunca como medio: primero, que la forma universal de los derechos exige la consideración igualitaria de las personas que son sus titulares; segundo, que el respeto hacia los derechos configura las bases axiológicas de las instituciones democráticas; tercero, que la garantía de los derechos por parte del Estado se convierte en la condición necesaria para la convivencia pacífica; y cuarto, que los derechos humanos desempeñan en las relaciones entre particulares, de éstos con el Estado y entre los propios Estados el papel de la ley del más débil. De hecho, el orden en que Ferrajoli presenta estos criterios es explicativo; pero pareciera que el nexo entre los derechos y la democracia acaba subsumiendo a los restantes criterios axiológicos. En este último sentido, la forma universal de los derechos establece un vínculo necesario entre éstos y los valores democráticos; es decir, que aquéllos se convierten en una vía para conseguir la igualdad, la paz y la protección jurídica del más débil frente al abuso del más fuerte -todas características de los regímenes democráticos. Como se señalo a propósito del segundo vértigo argumental - la impronta moral de los conceptos jurídicos-, las críticas comunitaristas y/o relativistas cuestionan la posibilidad de lograr una efectiva aplicación universal de los derechos a causa de la distancia entre las sociedades occidentales que los han gestado y los países en vía de democratización con diferentes sistemas de creencias y formas de vida. No obstante, aquí se pierde de vista la relación necesaria entre derechos y democracia. Más bien, según Ferrajoli, lo que se debería cuestionar es el tipo de valores que se pretenden realizar en la práctica política con el ejercicio del derecho. Los fines de la práctica política son ajenos a la definición teórica de 'derechos fundamentales', [la cual] se limita a señalar, en la forma universal asignada a los derechos que se quiere tutelar como fundamentales, el medio para alcanzarlos ${ }^{34}$.

En las sociedades modernas, los derechos positivizados en Constituciones son el fundamento jurídico y político del Estado de derecho pero, en opinión de Ferrajoli, éste es un criterio his-

\footnotetext{
33 Ibid. p. 225.

${ }^{34}$ Ferrajoli, Luigi (2001), "Los fundamentos de los derechos fundamentales”, en: Los fundamentos de los derechos fundamentales, ed. de Antonio de Cabo y Gerardo Pisarello, Trotta, Madrid, p. 318.
} 
tórico que desborda la conceptualización teórica de tales derechos. La coincidencia entre los fundamentos histórico y axiológico del uso instrumental de los derechos en la modernidad es totalmente contingente en el plano teórico y, por tanto, se incurriría en la falacia naturalista si se le afirmara como necesaria. Pero en la práctica política tal coincidencia no es contingente, sino expresión de los esfuerzos de los gobiernos posteriores a la Segunda Guerra Mundial por evitar la guerra al exterior y las revoluciones intestinas provocadas por la ausencia de protecciones efectivas para sus ciudadanos.

Ahora bien, la forma fundamental de expresión del vínculo entre los derechos humanos y la democracia se expresa en que - para la vida política institucionalizada - tales derechos con rango constitucional imponen límites a la legislación y -en consecuencia y si dichas instituciones son representativas - también a la democracia. Así, puede decirse que lo que es forma de la democracia se vuelve sustancia, es decir, límite y vínculo de contenido, cuando ella se protege de sí misma ${ }^{35}$. Lo anterior es así por tres razones. Primero, porque los derechos en una democracia constitucional - en oposición a las formas plebiscitaria o absoluta de la misma - limitan la actuación de los sujetos entre sí y en su interacción con los otros y, además, vinculan de una manera imparcial y equitativa a las instituciones y los ciudadanos. Según Ferrajoli, de no existir estos límites, la mayoría - si es convencida incluso por las peores razones morales, como ha sucedido históricamente con el fascismo y el nazismo que alcanzaron el poder en elecciones ordinarias-, podría decidir la disolución de la democracia anulando en algunos sujetos estigmatizados por la discriminación la capacidad de autodeterminación en lo privado y lo público. Segundo, una buena razón para llamar democráticos a los límites impuestos a la voluntad popular por los derechos fundamentales es que éstos son el parámetro más importante de la igualdad jurídica. Los derechos fundamentales son, en principio, universalmente válidos, es decir, para todas las personas y no se protegen constitucional y exclusivamente para quienes temporalmente ocupan el poder como mayoría. Por ello, la democracia no es sólo un método sino la puesta en marcha del ideal igualitario. Para Bobbio la revolución copernicana del derecho moderno significó la primacía de los derechos inalienables de los ciudadanos - como anteriores al pacto de sujeción-sobre los deberes emanados de la obligación política; a este proceso, correspondería una imagen paralela: la de la primacía de los derechos sobre los poderes fácticos. Tercero - y más importante-, deben acentuarse los límites que imponen los derechos a la democracia porque así se actualiza la idea en el sentido de la superioridad del gobierno de las leyes frente al de los hombres - aunque sea elegido democráticamente- $y$, además, porque se reconoce la importancia de los límites jurídicos que deben ser impuestos a los derechos de autonomía. Esto significa que, en un régimen político que ostenta el nombre de democrático, nadie puede vender ni comprar el derecho al voto, a la libertad de expresión o a la salud. Debido a la no disponibilidad de los derechos fundamentales en un régimen constitucional, éstos se sustraen a la autonomía política ejercida mediante el voto y la elección de representantes, mientras su carácter universal los sustrae a la autonomía privada, ejercida mediante actos de disposición de sus titulares ${ }^{36}$.

En este sentido, comprender y enseñar que el fundamento de los derechos humanos, aunque pueda deconstruirse histórica y sociológicamente, es sobre todo un asunto de convención política para fundamentar la práctica democrática, permitirá evaluar la manera en que el compromiso de un Estado con el paradigma garantista constituye, a la vez, un compromiso con la democratización de la vida pública.

\footnotetext{
35 Ibid. p. 344 .

${ }^{36}$ Ibid. p. 349. 


\section{Conclusión: La enseñanza de los derechos humanos como una tarea de comprensión política}

En este ensayo hemos tratado de mostrar cómo la comprensión y enseñanza de los derechos humanos es un fenómeno que no sólo consiste en la transmisión de conocimientos, en la construcción de una familiaridad cada vez mayor con los autores y tradiciones en torno a dicho paradigma o en el tratamiento de los instrumentos normativos que los enuncian como si fueran textos incontrovertibles o incapaces de ser enriquecidos con las nuevas demandas de inclusión y reconocimiento formuladas por los movimientos sociales emergentes. Nuestra hipótesis ha sido que la comprensión y enseñanza de los derechos humanos es, sobre todo, una tarea política que implica pensar reflexivamente y de manera simultánea la dimensión teórica y práctica de los problemas que definen este campo de estudio. Quienes nos acercamos a los derechos con curiosidad intelectual y con la necesidad de interpretar nuestro tiempo e instituciones a la luz de los enfoques con en el pasado se ha abordado el tema, también formamos parte de comunidades políticas que buscan la mejor forma de proteger la dignidad y dar expresión a los conceptos morales de autonomía, igualdad y libertad que la modernidad ilustrada formuló en clave universalista. Y lo hacemos desde la pérdida de la inocencia política respecto de la posibilidad de que el mal radical no vuelva a recurrir o de que escenarios como el campo de concentración o el gulag sean sólo el preámbulo de espacios donde se vulneren los derechos de manera más dramática. Por todo ello, consideramos que comprender y enseñar derechos humanos es una tarea que requiere enfrentarnos —en los ámbitos académicos, pero también en los espacios públicos-con los vértigos argumentales que han definido esta asignatura.

Volviendo con Arendt, habría que señalar que a ella los procesos educativos le parecían el marco institucionalizado en el que se podrían desarrollar tres tareas específicas a propósito de la comprensión de las modalidades de vulneración totalitaria de la dignidad y los derechos: primero, permitir a las personas más jóvenes reconocer su posición como herederas de una tradición política que les ha precedido y que ha realizado una promesa de liberación del autoritarismo que aún no está resuelta en la modernidad tardía; segundo, entender su inserción en un mundo de instituciones y prácticas discursivas plurales que requieren ser protegidas para que la ideología totalitaria no pueda dominar de nuevo el espacio público; y, tercero, pensar su propia localización como agentes con la capacidad de innovación y de discurso que en el pasado permitió a ciertas personas constituir el poder político compatible con la pluralidad mundana. Si bien esto no significa que la enseñanza condiciona el comportamiento políticamente responsable y cívico - pues la fragilidad de la acción política radica, precisamente, en la improbabilidad de su concreción en un contexto como la modernidad tardía, donde la autonomía de la política es amenazada por la colonización de los imperativos económicos o los criterios homogeneizantes de lo social-, lo cierto es que para Arendt educar significa acompañar a las personas para que ellas encuentren su lugar entre las ideas, las tradiciones y los ejemplos de acciones políticamente responsables del pasado. Para preservar la posibilidad que representa cada nueva generación en el sentido de romper con el pasado autoritario y comprometerse con la creación de las condiciones para el aseguramiento universal del derecho a tener derechos, la educación "tiene que preservar ese elemento nuevo e introducirlo como novedad en un mundo viejo que, por muy revolucionarias que sean sus acciones, siempre es anticuado y está cerca de la ruina desde el punto de vista de la última generación" 37.

37 Arendt, Hannah, Entre el pasado y el futuro, op. cit. p. 296. 


\section{Bibliografía}

Arendt, Hannah (2004), Los orígenes del totalitarismo, Taurus, México. (2003), Conferencias sobre la filosofía política de Kant, Paidós, Barcelona. (200o), Eichmann en Jerusalén. Un estudio sobre la banalidad del mal, $3^{\circ}$ edición, Lumen, Madrid. (1997), ¿Qué es la política?, Paidós, Barcelona, 1997. (1996), Entre el pasado y el futuro. Ocho ejercicios sobre la reflexión política, Península, Barcelona, 1996. (1995), De la historia a la acción, Paidós, Barcelona, 1995.

Benhabib, Seyla, (2001), Dignity in Adversity. Human Rights in Turbulent Times, Polity, Londres.

Bоввіо, Norberto (2003), Teoría general de la política, Trotta, Madrid, 2003. (1990), El tiempo de los derechos, Sistema, Madrid.

Cruz Parcero, Juan Antonio (2012), El lenguaje de los derechos. Ensayos para una teoría estructural de los derechos, Trotta, Madrid.

Dussel, Enrique (1998), Ética de la liberación en la edad de la globalización y la exclusión, Trotta, Madrid.

Ferrajoli, Luigi (2001), "Los fundamentos de los derechos fundamentales", en: Los fundamentos de los derechos fundamentales, ed. de Antonio de Cabo y Gerardo Pisarello, Trotta, Madrid.

Garzón VALDÉs, Ernesto (2000), "El consenso democrático: Fundamento y límites del papel de las minorías”, en: Isonomía, núm. 12, México, ITAM.

Habermas, Jünger (200o), Facticidad y validez. Sobre el derecho y el Estado democrático de derecho en términos de teoría del discurso, 2da. ed, Trotta, Madrid.

Hunt, Lynn (2009), La invención de los derechos humanos, Tusquets, Barcelona, 2009.

Lara, María Pía, Narrar el mal. Una teoría posmetafísica del juicio reflexionante, Gedisa, Barcelona.

MAKKreel, Rudolf A. (1990), Imagination and Interpretation in Kant: The Hermeneutical Import of The Critique of Judgment, University of Chicago Press, Chicago.

Moyn, Samuel (2010), The Last Utopia, The Belknap Press of Harvard University Press, Cambridge. 
Nussbaqum, Martha C. (2003), La terapia del deseo. Teoría y práctica en la ética helenística, Paidós, Barcelona.

Pereda, Carlos (1994), Vértigos argumentales. Una ética de la disputa, Anthropos/ UAM-Iztapalapa, México.

PÉrez, Sergio (2001), “La arqueología y la genealogía tal como yo las entiendo”, en: Estudios Políticos, núm. 18, Medellín, Universidad de Antioquia.

Platón (2014), Apología, Gredos, Madrid. (2014), República, Gredos, Madrid.

Popper, Karl (1957), La sociedad abierta y sus enemigos, Paidós, Buenos Aires.

Rodríguez ZEPEDA, Jesús (2004), Estado y transparencia. Un paseo por la filosofía política, IFAI, México.

Salazar, Luis (1997), El síndrome de Platón. ¿Hobbes o Spinoza?, UAM-Azcapotzalco, México. SERret, Estela (2002), Identidad femenina y proyecto ético, PUEG/ UAM-Azcaptzalco, México. 